\title{
Auflösung
}

\section{Einseitige Choanalatresie}
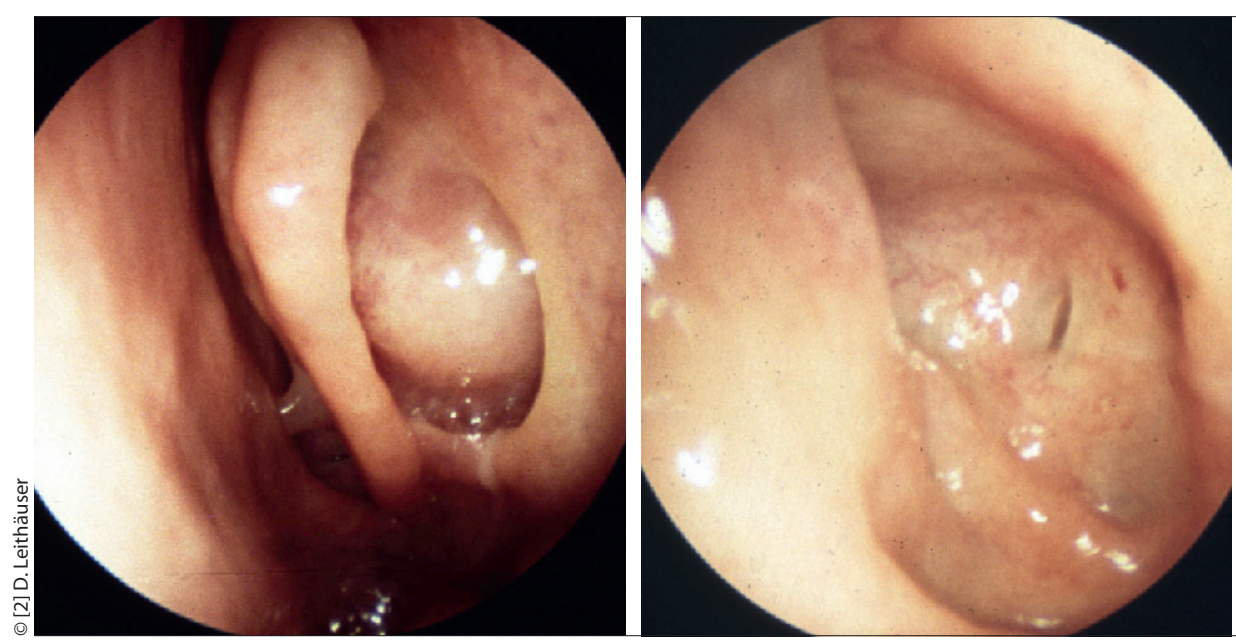

Bis auf eine kleine schlitzförmige Öffnung ist der Luftstrom durch die membranöse Choanalatresie fast vollständig behindert.

Klinik

Der endoskopische Befund der hinteren Nasenabschnitte zeigt die überraschende Ursache der Polyposis: eine membranöse Choanalatresie mit einem fast vollständigen Verschluss. Eine schlitzförmige Öffnung ermöglicht einen geringen Luftstrom

\section{Diagnostik}

Doppelseitige Choanalatresien werden durch den gestörten Trink- und Atemvorgang bei einem Neugeborenen schon in den ersten Lebenstagen erkannt und sofort operativ behandelt. Einseitige Atresien können lange unerkannt bleiben und äußern sich mit einer einseitigen, meist eitrigen Nasensekretion. Auf Grund der daraus resultierenden chronischen Entzündungszustände entstehen chronisch polypöse Schwellungen der Schleimhaut.

\section{Therapie}

Die vorgeschlagenen operativen Maßnahmen, die aus diesem Befund resultieren, wurden von der Patientin strikt abgelehnt.

\section{Dr. med. Dieter Leithäuser}

Warburg

\section{Blickdiagnosen auf springermedizin.de}

